\title{
Pirfenidone inhibits proliferation, arrests the cell cycle, and downregulates heat shock protein-47 and collagen type $I$ in rat hepatic stellate cells in vitro
}

\author{
XIAN-HONG XIANG $^{1 *}$, TIAN-PENG JIANG ${ }^{2 *}$, SHUAI ZHANG ${ }^{3}$, JIE SONG $^{2}$, \\ XING $\mathrm{LI}^{2}$, JIAN-YONG YANG ${ }^{1}$ and $\mathrm{SHI} \mathrm{ZHOU}^{2}$
}

\author{
${ }^{1}$ Department of Interventional Radiology, The First Affiliated Hospital of Sun Yat-Sen University, Guangzhou, \\ Guangdong 510080; ${ }^{2}$ Department of Interventional Radiology, Affiliated Hospital of Guiyang Medical College; \\ ${ }^{3}$ Department of Interventional Radiology, Affiliated Cancer Hospital of Guiyang Medical College, \\ Guiyang, Guizhou 550000, P.R. China
}

Received March 28, 2014; Accepted January 26, 2015

DOI: $10.3892 / \mathrm{mmr} .2015 .3403$

\begin{abstract}
Pirfenidone (esbiret) is an established anti-fibrotic and anti-inflammatory drug used to treat idiopathic pulmonary fibrosis. In the present study, the dose-dependent effects of pirfenidone on the cell cycle, proliferation and expression of heat shock protein (HSP)-47 and collagen type I in a cultured rat hepatic stellate cell line (HSC-T6) were investigated. Following pirfenidone treatment, cell proliferation was determined using the cell counting kit- 8 assay and the cell cycle was measured using flow cytometry. HSP-47 expression was estimated using western blot analysis and collagen type I mRNA was assessed using reverse transcription quantitative polymerase chain reaction. Pirfenidone induced significant dose-dependent inhibition of proliferation in HSC-T6 cells. Cell viability was unaffected by treatment with pirfenidone $(0$, 10 or $100 \mu \mathrm{M}$ ) for 24 and $72 \mathrm{~h}$. However, after $24 \mathrm{~h}$, HSC-T6 cells exhibited dose-dependent decreases in HSP-47 protein and collagen I mRNA levels. In conclusion, pirfenidone inhibited HSC-T6 cell proliferation, arrested the cell cycle and reduced the expression of HSP-47 and collagen type I,
\end{abstract}

Correspondence to: Dr Jian-Yong Yang, Department of Interventional Radiology, The First Affiliated Hospital of Sun Yat-Sen University, 58 Zhongshan Road II, Guangzhou, Guangdong 510080, P.R. China

E-mail: cjr.yangjianyong@vip.163.com

Dr Shi Zhou, Department of Interventional Radiology, Affiliated Hospital of Guiyang Medical College, 28 Guiyi Road, Guiyang, Guizhou 550000, P.R. China

E-mail: zhoushi_55@163.com

"Contributed equally

Key words: hepatic stellate cells, pirfenidone, collagen type I, heat shock protein-47, liver fibrosis, cell division indicating that pirfenidone may be a promising drug in the treatment of liver fibrosis.

\section{Introduction}

Liver fibrosis involves an excessive accumulation of extracellular matrix proteins, including collagen. It occurs in the majority of chronic liver diseases and hepatic stellate cells (HSCs) are the principal cell type responsible for liver fibrosis. Following the onset of a liver injury, quiescent HSCs become activated and transform into proliferative, fibrogenic and contractile myofibroblasts (1), which synthesize and secrete collagens (2). Therefore, HSCs have recently become a therapeutic target for liver fibrosis (3).

Heat shock protein (HSP)-47, a collagen-specific molecular chaperone, is predominantly present in the endoplasmic reticulum (ER) of collagen-producing cells and is also involved in the processing and/or secretion of procollagen (4-6). Expression of HSP-47 is upregulated in the fibrosis of various tissues (4), including liver cirrhosis (7), pulmonary fibrosis (8) and renal fibrosis (5). It has been reported that small interfering RNA targeting of HSP-47 in experimental liver fibrosis suppressed the expression and secretion of collagen in vivo and in vitro (9).

Pirfenidone [5-methyl-1-phenyl-2-(1H)-pyridone] is a novel anti-fibrotic and anti-inflammatory agent, which inhibits the progression of fibrosis in organs, including the lungs $(8,10)$, liver $(11,12)$, kidney $(13)$, heart $(14)$ and eyes $(15,16)$. It inhibits cytokines, including transforming growth factor-(TGF)- $\beta$ (16) and connective tissue growth factor (13,17-20). The compound also downregulates the expression of HSP-47 in human lung fibroblasts (8) and inhibits proliferation, cell migration and epithelial-mesenchymal transition of human lens epithelial cells. To the best of our knowledge, no information is available regarding the effects of pirfenidone on HSCs.

The aim of the present study was to investigate the effects of different concentrations of pirfenidone on rat hepatic stellate cells (HSC-T6), with a particular emphasis on cell morphology, proliferation, the cell cycle and expression of the proteins HSP-47 and collagen I. 


\section{Materials and methods}

Cell culture. HSC-T6 cells were obtained from The Third University Hospital of Sun Yat-Sen University cell bank (Guangzhou, China). The cells were maintained in Dulbecco's Modified Eagle's Medium (DMEM/F12; Hyclone, Logan, UT, USA) supplemented with $10 \%$ fetal bovine serum (FBS; Sijiqing Biological Engineering Materials, Hangzhou, China), $100 \mathrm{U} / \mathrm{ml}$ penicillin and $100 \mu \mathrm{g} / \mathrm{ml}$ streptomycin (Biochrom $\mathrm{GmbH}$, Berlin, Germany). The cells were maintained at $37^{\circ} \mathrm{C}$ in $5 \% \mathrm{CO}_{2}$ in a humidified atmosphere. All experiments were performed following 3-5 cell passages. Pirfenidone was purchased from Sigma-Aldrich (St. Louis, MO, USA).

HSC-T6 cells were cultured in six-well plates $\left(10^{5}\right.$ cells/well $)$ in DMEM/F-12 with $10 \%$ FBS. When cells grew to $80 \%$ confluence, the media was changed to DMEM/F-12 without penicillin or streptomycin but containing pirfenidone $(0,10$ and $100 \mu \mathrm{M}$ ) and growth was continued for $24 \mathrm{~h}$, following which cell morphology was examined under the optical microscope (DP22; Olympus, Tokyo, Japan).

Cell counting kit (CCK)-8 assay. HSC-T6 cells were seeded in 96 -well plates $\left(10^{5}\right.$ cells/well) for $24 \mathrm{~h}$ in DMEM/F-12 with $10 \%$ FBS. When cells grew to $80 \%$ confluence, they were incubated in DMEM/F-12 supplemented with pirfenidone $(0,10$ and $100 \mu \mathrm{M})$ for $24 \mathrm{~h}$. Following incubation with $100 \mu \mathrm{l}$ DMEM/F-12 and $10 \mu \mathrm{l} \mathrm{CCK-8} \mathrm{solution} \mathrm{(Beyotime} \mathrm{Institute} \mathrm{of}$ Biotechnology, Shanghai, China) for $1 \mathrm{~h}$ at $37^{\circ} \mathrm{C}$, the absorbance at $450 \mathrm{~nm}$ was measured using a microplate reader (Meterterch $\Sigma 960$; Sigma-Aldrich).

Flow cytometry. After a 24-h incubation in DMEM/F-12 with $10 \%$ FBS, HSC-T6 cells were incubated with pirfenidone $(0,10$ or $100 \mu \mathrm{M})$ for an additional $24 \mathrm{~h}$, then trypsinized, washed in phosphate-buffered saline (PBS) and fixed with $70 \%$ cold methanol $\left(4^{\circ} \mathrm{C}\right)$ overnight. Following fixation, the cells were washed to remove alcohol and resuspended in PBS containing $100 \mu \mathrm{g} / \mathrm{ml}$ RNase A (Wako Pure Chemicals Industries, Ltd., Osaka, Japan) at $37^{\circ} \mathrm{C}$ for $30 \mathrm{~min}$. The nuclei were stained by incubation in $50 \mu \mathrm{g} / \mathrm{ml}$ propidium iodide (Wako Pure Chemicals Industries, Ltd.) at $4^{\circ} \mathrm{C}$ for $30 \mathrm{~min}$ and analyzed by flow cytometry using a FACS Aria cell sorter (BD Biosciences, Franklin Lakes, NJ, USA). The cell cycle distribution was analyzed using Modifit software (BD Biosciences).

Western blot analysis. After a $24 \mathrm{~h}$ incubation in DMEM/F-12 with $10 \%$ FBS, HSC-T6 cells were treated with pirfenidone $(0,10$ or $100 \mu \mathrm{M})$ for an additional $24 \mathrm{~h}$. Cultured cells were harvested and lysed in mammalian protein extraction reagent (Pierce Biotechnology, Inc., Rockford, IL, USA). Supernatants obtained using centrifugation at $12,000 \mathrm{xg}$ for $30 \mathrm{~min}$ at $4^{\circ} \mathrm{C}$ were used as cytoplasmic extracts. Protein concentrations were determined using a bicinchoninic acid assay kit (Shanghai Shenergy Biocolor BioScience and Technology Company, Shanghai, China). Prepared samples were heated to $100^{\circ} \mathrm{C}$ for 5 min prior to $10 \%$ acrylamide SDS-PAGE (Amersham Biosciences, Freiburg, Germany), and an identical quantity of total protein $(20 \mu \mathrm{g})$ was added to each well. Separated proteins were transferred onto a nitrocellulose membrane (Hybond-ECL; Amersham Biosciences, Freiburg, Germany). Nonspecific binding was blocked by incubation with Tris-buffered saline with Tween 20 (TBST) containing 5\% nonfat milk for $2 \mathrm{~h}$ prior to an overnight incubation with a 1:1,000 dilution of the mouse monoclonal anti-human HSP-47 antibody (Stress Gen, Victoria, $\mathrm{BC}$, Canada) diluted in TBST at $4^{\circ} \mathrm{C}$ with constant agitation. Following several washes with TBST, the membranes were incubated with a 1:10,000 dilution of the anti-mouse immunoglobulin G secondary antibody (ZSGB-BIO, Beijing, China) for $1 \mathrm{~h}$. Following several subsequent washes with TBST, blots were developed using chemiluminescence (Phototope-HRP Western Blot Detection system; Cell Signaling Technology, Inc, Danvers, MA, USA) and the signal was captured on X-ray film (Eastman Kodak, Rochester, NY, USA) according to the manufacturer's instructions. The abundance of HSP-47 was correlated against a 1:10,000 dilution of mouse anti-GAPDH monoclonal antibody (Kang Chen Bio-tech Inc., Shanghai, China) and quantified using densitometry.

Reverse transcription quantitative polymerase chain reaction $(R T-q P C R)$. At $48 \mathrm{~h}$ after treatment with pirfenidone, total RNA was isolated from cultured cells using TRIzol reagent (Invitrogen Life Technologies, Carlsbad, CA, USA). The ThermoScript RT system (Fermentas, Burlington, ON, Canada) was used to conduct the RT reactions. Total RNA $(1 \mu \mathrm{g})$ was used for RT in a total volume of $20 \mathrm{ml}$. The following primers (mixed with probes) were purchased from Geneseed Biotech (Guangzhou, China): Collagen type I forward, 5'-CCCTACCCAGCACCTTCAAA-3' and reverse, 5'-GCAC AGGCCCTCAAAAACA-3'; and 18srRNA forward, 5'-CCTGGATACCGCAGCTAGGA-3' and reverse, 5'-GCGGCGCAATACGAATGCCCC-3'.

18S RNA as a control. PCR amplification was performed in a Gene Amp 2400 thermal cycler (Perkin Elmer Inc., Waltham, MA, USA). PCR amplification was performed with an initial denaturation step at $95^{\circ} \mathrm{C}$ for $5 \mathrm{~min}$, followed by 40 cycles of denaturation at $95^{\circ} \mathrm{C}$ for $15 \mathrm{sec}$, annealing at $60^{\circ} \mathrm{C}$ and extension at $72^{\circ} \mathrm{C}$ for $32 \mathrm{sec}$, with a final extension at $72^{\circ} \mathrm{C}$ for $32 \mathrm{sec}$. Quantification of signal intensity was confirmed using the IBAS 2.5 Auto Image analysis program (Kontron, Eching, Germany). The fidelity of the RT-PCR fragments was subsequently verified by comparing the size of the amplified products with the expected cDNA bands and the sequencing of the PCR products.

Statistical analysis. Values are expressed as the mean \pm standard deviation. All data were analyzed using a one-way analysis of variance and with the Bonferroni test for replicate measurements. Statistical analyses were conducted using SPSS version 17.0 (SPSS Inc., Chicago, IL, USA). A Bonferroni adjusted $\mathrm{P}<0.05$ was considered to indicate a statistically significant difference. For the Kontron IBAS 2.0 automatic image analysis system (Amersham Biosciences), semi-quantitative analysis was applied to scan strips. The stripe area and optical density were analyzed.

\section{Results}

Effects of pirfenidone on morphology of HSC-T6 cells. Under the optical microscope, the HSC-T6 cells were a characteristic myofibroblastic shape. In the medium containing penicillin and 
Control

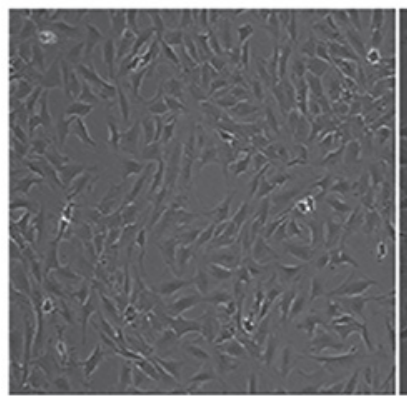

Pirfenidone $10 \mu \mathrm{m}$

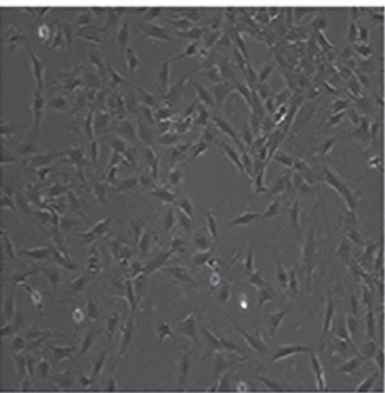

Pirfenidone $100 \mu \mathrm{m}$

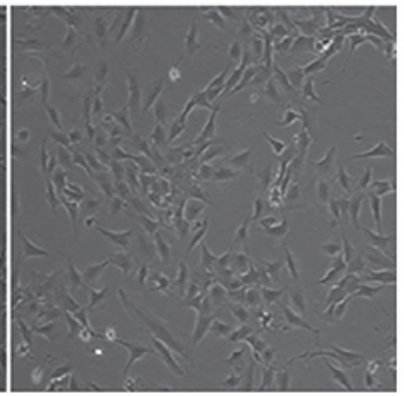

Figure 1. Morphological changes of HSC-T6 cells visualized using optical microscopy (magnification, x10). Following treatment with pirfenidone (10 or $100 \mu \mathrm{M}$ ) for $24 \mathrm{~h}$, cells were generally smaller in size and changed to a more slender cell shape. Cells numbers were also noticeably decreased compared with untreated cells.

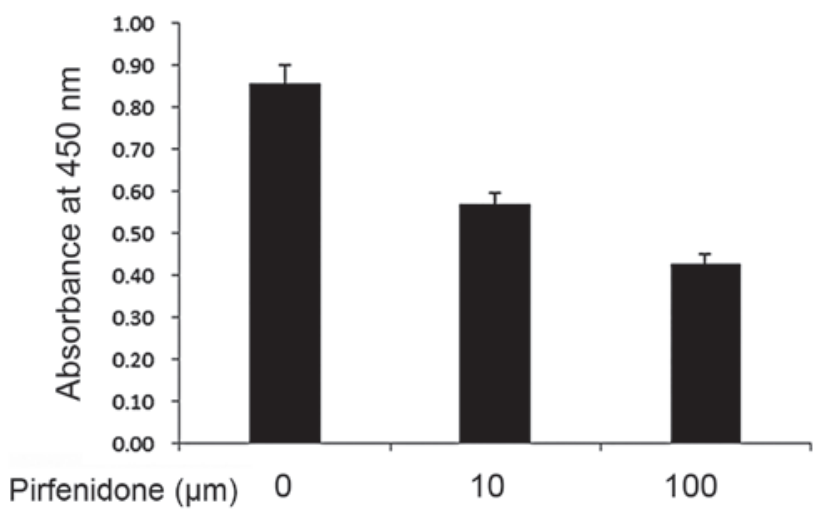

Figure 2. Proliferation of HSC-T6 cells following treatment with pirfenidone as measured using a cell counting kit- 8 assay. Cells in Dulbecco's modified Eagle's medium/F12 were treated with pirfenidone $(0,10$ or $100 \mu \mathrm{M})$ for $24 \mathrm{~h}$. Values are expressed as the mean \pm standard deviation of three independent experiments. The absorbance of cells decreased in a dose-dependent manner $(\mathrm{P} \leq 0.05)$.

\section{Control}

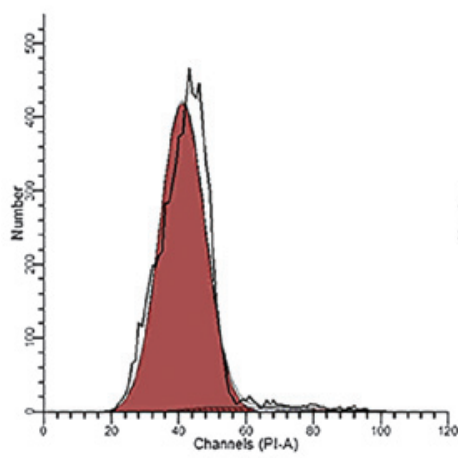

Pirfenidone $10 \mu \mathrm{m}$

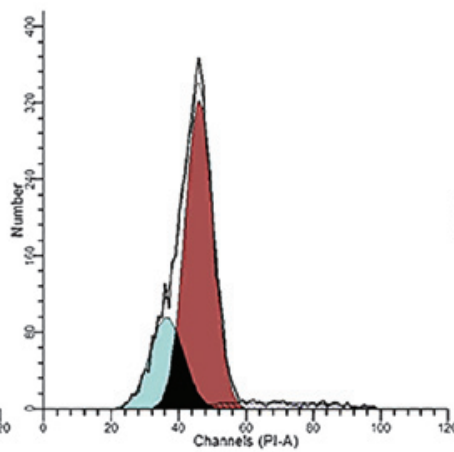

\section{Pirfenidone $100 \mu \mathrm{m}$}

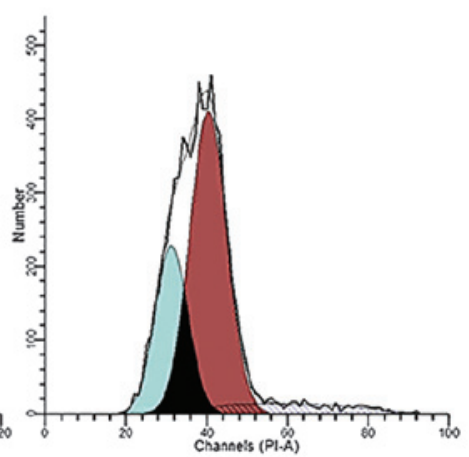

Figure 3. Flow cytometric analysis of the cell cycle. Pirfenidone arrested the cell cycle at the G1 phase in a dose-dependent manner. The percentage of cells in the S and G2 phase exhibited no marked differences among different concentrations of pirfenidone. Values are expressed as the mean \pm standard deviation of three independent experiments.

streptomycin, cells were observed to be attached to the culture plate and stretching pseudopodia were identified after $4 \mathrm{~h}$. By the following day, cells were more uniform, with slender pseudopodia. After two days, star-shaped cells were fully-fused. Following exposure to $10-100 \mu \mathrm{M}$ pirfenidone for $24 \mathrm{~h}$, cells were generally smaller in size and of a more slender shape (Fig. 1). In addition, quantities of the cells were markedly reduced (Fig. 2).
Effects of pirfenidone on cell proliferation. HSC-T6 cells were treated with pirfenidone $(0,10$ or $100 \mu \mathrm{M})$ for $24 \mathrm{~h}$ and cell proliferation was measured using the CCK- 8 assay. Pirfenidone significantly reduced the level of cell proliferation in a dose-dependent manner $(10 \mu \mathrm{M}$ pirfenidone vs. control, $\mathrm{P}=0.005 ; 100 \mu \mathrm{M}$ pirfenidone vs. control, $\mathrm{P}<0.001 ; 10 \mu \mathrm{M}$ vs. $100 \mu \mathrm{M}$ pirfenidone, $\mathrm{P}=0.0037$; Fig. 1). 

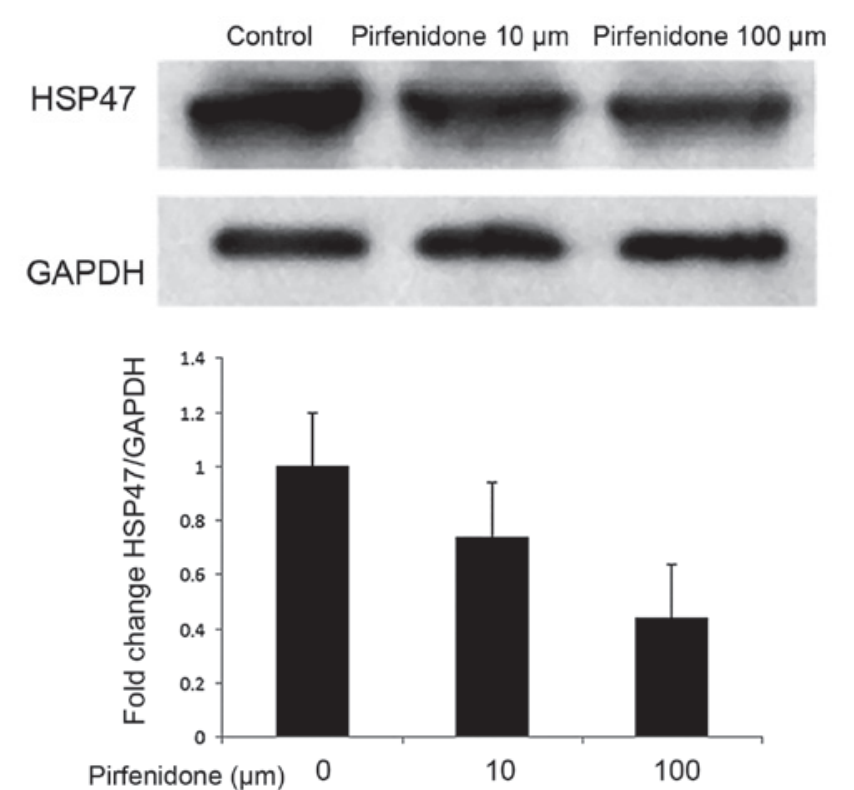

Figure 4. Effects of pirfenidone on heat shock protein-47 expression. Western blotting revealed protein production after $24 \mathrm{~h}$ incubation with pirfenidone $(0,10$ or $100 \mu \mathrm{M})$. Band densities were normalized against GAPDH and are shown as a ratio. Values are expressed as the mean \pm standard deviation of three independent experiments.

Effects of pirfenidone on the cell cycle. The cell cycle distribution was determined using flow cytometric analysis of released nuclei. Following treatment with pirfenidone for $24 \mathrm{~h}$, the proportion of cells in the G1 phase was decreased; however the number in the S-phase was increased (Fig. 3).

Effects of pirfenidone on HSP-47 expression. The effects of pirfenidone on HSP-47 expression were investigated using western blot analysis. The expression of HSP-47 was clearly decreased by pirfenidone treatment in a dose-dependent manner $(10 \mu \mathrm{M}$ pirfenidone vs. control, $\mathrm{P}=0.042$; $100 \mu \mathrm{M}$ pirfenidone vs. control, $\mathrm{P}=0.003 ; 10 \mu \mathrm{M}$ vs. $100 \mu \mathrm{M}$ pirfenidone, $\mathrm{P}=0.011$; Fig. 4A, B).

Effects of pirfenidone on expression of collagen type I. The mRNA levels of collagen type I were analyzed $24 \mathrm{~h}$ after pirfenidone treatment. Of note, collagen type I mRNA levels were significantly decreased by pirfenidone $(10 \mu \mathrm{M}$ pirfenidone vs. control, $\mathrm{P}=0.079 ; 100 \mu \mathrm{M}$ pirfenidone vs. control, $\mathrm{P}=0.017$; $10 \mu \mathrm{M}$ vs. $100 \mu \mathrm{M}$ pirfenidone, $\mathrm{P}=0.044$; Fig. 5). Furthermore, quantitative analysis of collagen I transcription normalized against 18S RNA exhibited a similar dose-dependent pattern to that observed with HSP-47 expression (Fig. 4). This indicated that a reduction of collagen type I mRNA resulted from the decreased HSP-47 protein levels caused by pirfenidone treatment.

\section{Discussion}

The final stage of liver fibrosis is liver cirrhosis, which results in severe hepatic incapacity and portal hypertension (21). Liver fibrosis is reversible and there are a number of specific therapies, including antiviral treatments for patients infected with hepatitis B or C (22). Mesenchymal stem cell injection (23) is
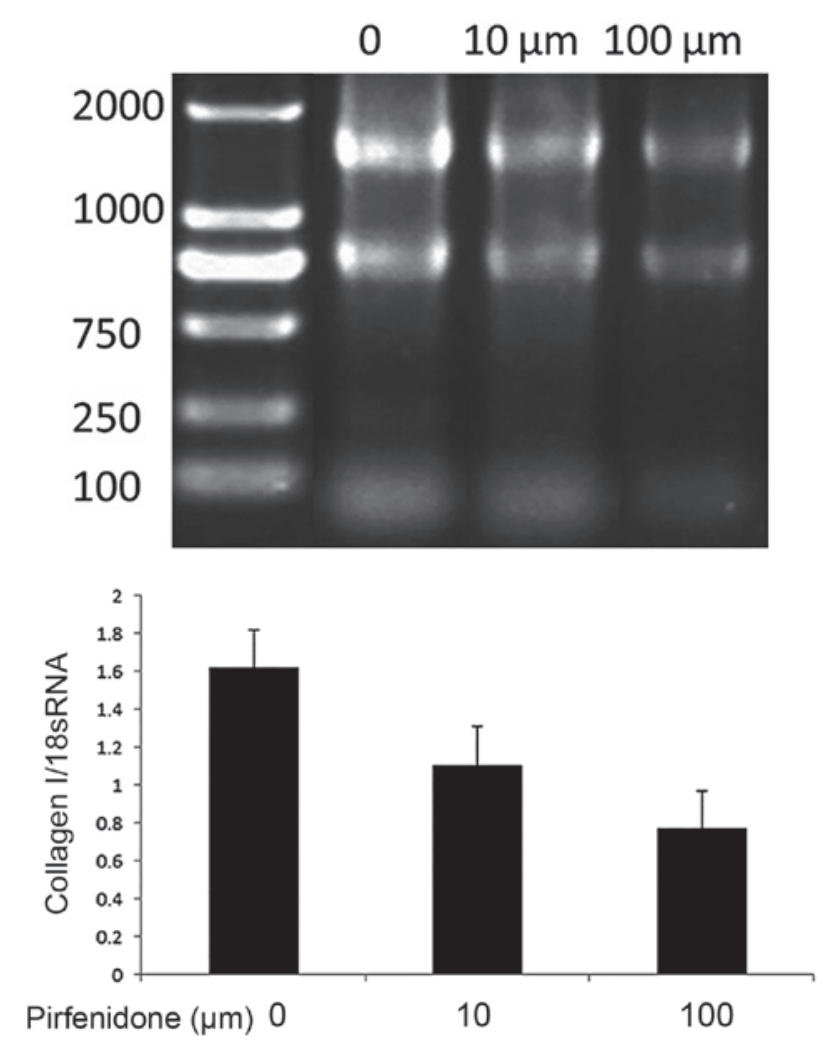

Figure 5. Effects of pirfenidone on collagen type I mRNA expression in HSC-T6 cells. Reverse transcription-polymerase chain reaction demonstrating mRNA expression of collagen type I after $24 \mathrm{~h}$ incubation with pirfenidone $(0,10$ or $100 \mu \mathrm{M})$. Band densities were normalized against 18S RNA and are shown as a ratio. Values are expressed as the mean \pm standard error of the mean of three independent experiments.

also available, but no specific and effective anti-fibrotic therapies have been developed to date.

Pirfenidone, a small and orally bioavailable molecule, was approved for mild to moderate idiopathic pulmonary fibrosis in the European Union in February 2011 and in Japan in 2009 (24). The anti-fibrotic effects of pirfenidone have been demonstrated in different experimental models of liver fibrosis, and also with dimethylnitrosamine (25-28). Treatment with pirfenidone reduced the expression of fibrotic genes, including TGF- $\beta$, profibrogenic procollagen $\alpha 1(\mathrm{I})$ and TIMP-1. In an in vitro study of liver fibrosis, this drug was effective at inhibiting platelet-derived growth factor-induced proliferation of HSCs, and the expression and accumulation of collagen type I induced by TGF- $\beta 1$ (17). However, the expression and accumulation of collagens are not only induced by TGF- $\beta 1$, but also regulated by a variety of cytokines and cell signaling pathways during this complex multi-system pathological process; therefore, the precise in vitro molecular effects of pirfenidone on collagen synthesis in liver fibrosis require further elucidation. In the present study, pirfenidone suppressed HSC-T6 cell proliferation in a dose-dependent manner. Optical microscopy revealed that following treatment with pirfenidone for $24 \mathrm{~h}$, HSC-T6 cells became smaller in size and decreased in number. Flow cytometry of the cells revealed that pirfenidone treatment significantly modified the cell cycle. A lower concentration of pirfenidone $(10 \mu \mathrm{M})$ altered the cell cycle in a dose-dependent manner, although changes were subtle. However, at $100 \mu \mathrm{M}$, the proportion of cells in the G1 
phase was significantly decreased, suggesting the compound induced cell cycle arrest at G1 phase. The effect of pirfenidone on the cell cycle of different cells using different treatments has been reported previously. Pirfenidone arrested Tenon cells in G1 phase to inhibit cell proliferation (16), but Leiomyoma cells were not affected (25). Due to the highly complex and tightly regulated nature of the cell cycle itself, the effects of pirfenidone on HSC-T6 and other cells requires further investigation.

Pirfenidone was also observed to inhibit the expression of HSP-47 and collagen type I in a dose-dependent manner, as revealed by western blot analysis and RT-qPCR, respectively. HSP-47, as a collagen-specific molecular chaperone, has an essential role in the maturation of various procollagens $(4,29,30)$. Upregulation of HSP-47 has been revealed to be correlated with an increased accumulation of collagens in fibrosis of the liver (7), lung (31), kidney (32), heart (33) and skin (34). In these studies, HSP-47 was revealed to affect the abnormal accumulation of collagen type I and collagen type III, two of the most important extracellular matrix proteins. These in vivo and in vitro studies demonstrated that anti-sense oligodeoxynucleotides against HSP-47 were able to inhibit collagen production $(9,35-38)$. In lung fibroblasts, pirfenidone suppressed the increased expression of HSP-47 in vivo (10) and in vitro (8). In the present study, pirfenidone exhibited a similar suppressive effect on the expression of HSP-47 in HSC-T6 cells. The downregulation of HSP-47 collagen type I was most pronounced following treatment with $100 \mu \mathrm{M}$ pirfenidone. This downregulation and the possible reduction of collagen synthesis during liver fibrosis is likely to explain the anti-fibrotic effects of this compound.

In conclusion, pirfenidone exhibited inhibitory effects on the proliferation of rat HSC-T6 cells, decreased the proportion of cells in G1 phase and increased the number of cells in S phase. In addition, pirfenidone significantly suppressed HSP-47 protein and collagen type I expression in vitro. Pirfenidone may be used to regulate the expression of HSP-47 in HSC-T6 cells and is a potential therapeutic agent for liver fibrosis.

\section{Acknowledgements}

The present study was supported by the research Fund for the Doctoral Program of Higher Education of China (grant no. 20120171120086) and the Science and Technology Planning Project of Guangdong Province (grant no. 2012B061700078).

\section{References}

1. Friedman SL: Molecular regulation of hepatic fibrosis, an integrated cellular response to tissue injury. J Biol Chem 275: 2247-2250, 2000.

2. Milani S, Herbst H, Schuppan D, Surrenti C, Riecken EO and Stein H: Cellular localization of type I III and IV procollagen gene transcripts in normal and fibrotic human liver. Am J Pathol 137: 59-70, 1990

3. Bataller R and Brenner DA: Liver fibrosis. J Clin Invest 115: 209-218, 2005

4. Taguchi T and Razzaque MS: The collagen-specific molecular chaperone HSP47: Is there a role in fibrosis. Trends Mol Med 13: 45-53, 2007.

5. Razzaque MS, Le VT and Taguchi T: Heat shock protein 47 and renal fibrogenesis. Contrib Nephrol 148: 57-69, 2005.
6. Chen JJ, Jin PS, Zhao S, Cen Y, Liu Y, Xu XW, Duan WQ and Wang HS: Effect of heat shock protein 47 on collagen synthesis of keloid in vivo. ANZ J Surg 81: 425-430, 2011.

7. Brown KE, Broadhurst KA, Mathahs MM, Brunt EM and Schmidt WN: Expression of HSP47, a collagen-specific chaperone, in normal and diseased human liver. Lab Invest 85: 789-797, 2005.

8. Nakayama S, Mukae H, Sakamoto N, et al: Pirfenidone inhibits the expression of HSP47 in TGF- $\beta 1$-stimulated human lung fibroblasts. Life Sci 82: 210-217, 2008.

9. Sato Y, Murase K, Kato J, et al: Resolution of liver cirrhosis using vitamin A-coupled liposomes to deliver siRNA against a collagen-specific chaperone. Nat Biotechnol 26: 431-442, 2008.

10. Kakugawa T, Mukae H, Hayashi T, Ishii H, Abe K, Fujii T, Oku H, Miyazaki M, Kadota J and Kohno S: Pirfenidone attenuates expression of HSP47 in murine bleomycin-induced pulmonary fibrosis. Eur Respir J 24: 57-65, 2004.

11. Zhao XY, Zeng X, Li XM, Wang TL and Wang BE: Pirfenidone inhibits carbon tetrachloride- and albumin complex-induced liver fibrosis in rodents by preventing activation of hepatic stellate cells. Clin Exp Pharmacol Physiol 36: 963-968, 2009.

12. Armendáriz-Borunda J, Rincón AR, Muñoz-Valle JF, et al: Fibrogenic polymorphisms (TGF-beta, PAI-1, AT) in Mexican patients with established liver fibrosis. Potential correlation with pirfenidone treatment. J Investig Med 56: 944-953, 2008.

13. Hewitson TD, Kelynack KJ, Tait MG, Martic M, Jones CL, Margolin SB and Becker GJ: Pirfenidone reduces in vitro rat renal fibroblast activation and mitogenesis. J Nephrol 14: 453-460, 2001.

14. Miric G, Dallemagne C, Endre Z, Margolin S, Taylor SM and Brown L: Reversal of cardiac and renal fibrosis by pirfenidone and spironolactone in streptozotocin-diabetic rats. Br J Pharmacol 133: 687-694, 2001.

15. Sun G, Lin X, Zhong H, Yang Y, Qiu X, Ye C, Wu K and Yu M: Pharmacokinetics of pirfenidone after topical administration in rabbit eye. Mol Vis 17: 2191-2196, 2011.

16. Lin X, Yu M, Wu K, Yuan $\mathrm{H}$ and Zhong $\mathrm{H}$ : Effects of pirfenidone on proliferation, migration, and collagen contraction of human Tenon's fibroblasts in vitro. Invest Ophthalmol Vis Sci 50: 3763-3770, 2009.

17. Di Sario A, Bendia E, Svegliati Baroni G, et al: Effect of pirfenidone on rat hepatic stellate cell proliferation and collagen production. J Hepatol 37: 584-591, 2002.

18. Gurujeyalakshmi G, Hollinger MA and Giri SN: Pirfenidone inhibits PDGF isoforms in bleomycin hamster model of lung fibrosis at the translational level. Am J Physiol 276: L311-L318, 1999.

19. Grattendick KJ, Nakashima JM, Feng L, Giri SN and Margolin SB: Effects of three anti-TNF-alpha drugs: Etanercept, infliximab and pirfenidone on release of TNF-alpha in medium and TNF-alpha associated with the cell in vitro. Int Immunopharmacol 8: 679-687, 2008.

20. Oku H, Nakazato H, Horikawa T, Tsuruta Y and Suzuki R: Pirfenidone suppresses tumor necrosis factor-alpha, enhances interleukin-10 and protects mice from endotoxic shock. Eur J Pharmacol 446: 167-176, 2002.

21. Ginès P, Cárdenas A, Arroyo V and Rodés J: Management of cirrhosis and ascites. N Engl J Med 350: 1646-1654, 2004.

22. Rockey DC: Current and future anti-fibrotic therapies for chronic liver disease. Clin Liver Dis 12: 939-962, xi, 2008.

23. Zhao W, Li JJ, Cao DY, Li X, Zhang LY, He Y, Yue SQ, Wang DS and Dou KF: Intravenous injection of mesenchymal stem cells is effective in treating liver fibrosis. World J Gastroenterol 18: 1048-1058, 2012.

24. Behr J: Idiopathic pulmonary fibrosis: Modern guideline-concordant diagnostics and innovative treatment. Dtsch Med Wochenschr 137: 601-604, 2012 (In German).

25. Salazar-Montes A, Ruiz-Corro L, López-Reyes A, Castrejón-Gómez E and Armendáriz-Borunda J: Potent antioxidant role of pirfenidone in experimental cirrhosis. Eur J Pharmacol 595: 69-77, 2008.

26. Di Sario A, Bendia E, Macarri G, Candelaresi C, Taffetani S, Marzioni M, Omenetti A, De Minicis S, Trozzi L and Benedetti A: The anti-fibrotic effect of pirfenidone in rat liver fibrosis is mediated by downregulation of procollagen alpha1(I), TIMP-1 and MMP-2. Dig Liver Dis 36: 744-751, 2004.

27. Tada S, Nakamuta M, Enjoji M, Sugimoto R, Iwamoto $H$, Kato M, Nakashima Y and Nawata H: Pirfenidone inhibits dimethylnitrosamine-induced hepatic fibrosis in rats. Clin Exp Pharmacol Physiol 28: 522-527, 2001. 
28. Navarro-Partida J, Martinez-Rizo AB, Gonzalez-Cuevas J, Arrevillaga-Boni G, Ortiz-Navarrete V and Armendariz-Borunda J: Pirfenidone restricts Th2 differentiation in vitro and limits Th2 response in experimental liver fibrosis. Eur J Pharmacol 678: 71-77, 2012.

29. Sauk JJ, Nikitakis N and Siavash H: Hsp47 a novel collagen binding serpin chaperone, autoantigen and therapeutic target. Front Biosci 10: 107-118, 2005.

30. Taguchi T, Nazneen A, Al-Shihri AA, Turkistani KA and Razzaque MS: Heat shock protein 47: A novel biomarker of phenotypically altered collagen-producing cells. Acta Histochem Cytochem 44: 35-41, 2011.

31. Nagata K: Therapeutic strategy for fibrotic diseases by regulating the expression of collagen-specific molecular chaperone HSP47. Nippon Yakurigaku Zasshi 121: 4-14, 2003 (In Japanese).

32. Xia Z, Abe K, Furusu A, Miyazaki M, Obata Y, Tabata Y, Koji T and Kohno S: Suppression of renal tubulointerstitial fibrosis by small interfering RNA targeting heat shock protein 47. Am J Nephrol 28: 34-46, 2008

33. Hagiwara S, Iwasaka H, Shingu C, Matumoto S, Hasegawa A and Noguchi T: Heat shock protein 47 (HSP47) antisense oligonucleotides reduce cardiac remodeling and improve cardiac function in a rat model of myocardial infarction. Thorac Cardiovasc Surg 59: 386-392, 2011.
34. Dams SD, de Liefde-van Beest M, Nuijs AM, Oomens CW and Baaijens FP: Heat shocks enhance procollagen type I and III expression in fibroblasts in ex vivo human skin. Skin Res Technol 17: 167-180, 2011

35. Sauk JJ, Smith T, Norris K and Ferreira L: Hsp47 and the translation-translocation machinery cooperate in the production of alpha 1(I) chains of type I procollagen. J Biol Chem 269: 3941-3946, 1994

36. Sunamoto M, Kuze K, Tsuji H, Ohishi N, Yagi K, Nagata K, Kita T and Doi T: Antisense oligonucleotides against collagen-binding stress protein HSP47 suppress collagen accumulation in experimental glomerulonephritis. Lab Invest 78: 967-972, 1998.

37. Hagiwara S, Nakamura K, Hamada H, et al: Inhibition of type I procollagen production by tRNAVal CTE-HSP47 ribozyme. J Gene Med 5: 784-794, 2003.

38. Nishino T, Miyazaki M, Abe K, Furusu A, Mishima Y, Harada T, Ozono Y, Koji T and Kohno S: Antisense oligonucleotides against collagen-binding stress protein HSP47 suppress peritoneal fibrosis in rats. Kidney Int 64: 887-896, 2003. 